first-class research work which is to-day being presented in an irrelevant matrix of Marxian philosophy. Catholics, and indeed Christians in general, are at fault in looking upon all forms of science with a timidity that is a relic of a past defensive attitude. There is a great need for more Christian men of science, especially biologists, who may oppose a truly personalist attitude to the decadent views falsely put forward as the answers of science to the human problems of marriage, education and family relationships. One of the most important steps to be taken is the proper education of medical men. The medical course is long, and commonly admits of few but professional studies, whereas it is most desirable that medical men should have some knowledge of sociology, the arts and the elements of philosophy. A preliminary year's course of humanistic studies would be of great value to men who will have so important a position in the social structure.

There followed a paper on "Science and Man" by Dr. H. P. Newsholme, professor of hygiene in the University of Birmingham. The most important effect of science on the community was its example of single-minded search for truth, and discarding of emotional and personal feelings; but this setting aside of all but the material aspect of things, though it arise from a recognition of the incapacity of science, may lead to the implicit assumption that the material aspect alone is worthy of consideration. This limitation of outlook has led to correspondingly defective results. Thus Freud did good service in opening up the subconscious, but failed to recognize in it an avenue of God's approach to man. In the region of the physical life and of social environment the debt of humanity to science has been incalculable. But though the health and comfort of man has been increased, the troubles of his spirit are left untreated.

The great prestige of science has led society to respect the opinions of its workers, and their implicit materialism has contributed to the formation of a materialistic society, which in turn rears more materialistic scientific workers. Not only science, but also almost every human activity, has become dissociated from religion, and the immediate consequence has been their exploitation by the selfish. Scientific agriculture has led to denudation and sterility; family limitation is depleting the population and degrading it by separating the pleasures of sex from its responsibilities. Furthermore, the exaltation of the physically fit as alone worthy of survival threatens the world with the arrangement of mating on physical grounds, with sterilization of the so-called unfit, and with euthanasia, which leads by a short step to the deliberate 'elimination' of the aged, mentally deficient or incurable. In the realm of ideas the effect has been even to extend natural law beyond its function, which is the summation of past events. Such events as find no place in the records of science, for example, miracles, such as the Resurrection, the greatest of them, are sometimes denied; and theories, such as that of organic evolution, are extended from body to mind. If science had retained its association with religion, it might have grown more slowly, but the product would have been richer and more significant, and the world would have been protected against the worst types of exploitation of the powers of science.

The final conference was presided over by the Right Rev. Bernard Griffin, Bishop Auxiliary of Birmingham. The Rev, Philip de Ternant contributed a paper on "The Place of Science in Educa- tion". His title, he said, was not science in the school, which is another subject. At the time of Alcuin the concept of a scholar was primitive but comprehensive. The old Trivium and Quadrivium contained the germ of scholasticism and of universities : it involved recognition of the unity of the universe and of the spirit of man. One idea may be seen to underlie these three forms of a single word. As material knowledge increased, specialization became necessary, but to-day's is much overdone in response to the utilitarian age. Our task is to create a reversion to the older type of scholar and to re-integrate the scattered elements of knowledge, now known only collectively as science. The great specialists are noteworthy for the breadth of their basic knowledge, but men of science generally lack philosophy to-day. The true purpose of a university has been disnatured by fetishes, popular and scholastic. The width of outlook and general interest formerly displayed in the older "Academes", from the Royal Society down to local field clubs, and in the followers of nature hobbies in the family circle itself, is much needed to-day.

The Rev. Philip de Ternant advocated the 'perennial' philosophy of St. Thomas Aquinas and his modern followers, such as Maritain, in opposition to the widespread aberrations of to-day, and asked for a primer or handbook on the subject adapted to the use of science students. He regretted the obscurantism of the public and of certain pious people. St. Thomas had established that the study of natural science is a religious duty, as leading us, first to consideration and admiration of the Divine.Wisdom, thence to reverence, fear and especially love, when the goodness and beauty of created things attracts the souls of men and leads to a comparison of the same things in a higher form in God; finally it sets up in men a certain similitude of the Divine perfection and wisdom. So, also, a wrong notion of the nature of creatures leads us to think they are all that exists, and that men are subject to laws which do not exist. So, argues St. Thomas, that opinion is false which says that it matters nothing to religious faith what anyone thinks of creatures, so long as he is right with God; for error concerning creatures leads to a false idea of God, and so leads minds away from Him. Therefore scripture threatens with penalties, as if they were pagans, those who have a false idea of natural facts: "Because they have not understood the works of the Lord, and the operations of his hands : thou shalt destroy them and shalt not build them up" (Ps. xxvii, 5).

\section{QUANTITATIVE AND QUALITATIVE METHOD IN SOCIOLOGICAL RESEARCH}

$\mathrm{T}$ HE principal item on the Saturday (April 11) meeting of the British Psychological Society at Brighton was the open discussion in the evening between Mr. Henry Durant of the British Institute of Public Opinion, and Mr. Tom Harrisson of MassObservation. Mr. Durant opened the discussion by supporting the proposition "that Empirical Methods in the Social Sciences should be Predominantly Quantitative".

Social scientists should, in their empirical work, 
endeavour to employ methods and concepts producing quantitative results. In Mr. Durant's view, organized science in the physical world is based upon - measurement. These measurements can be tested and verified because they are based upon units of measurement which are objective and can be handled by any investigator. By insisting upon the quantitative method and developing its use in every direction possible, more and more phenomena are being reduced to quantitative terms. Biology took an immense step forward when genetics with its statistical basis was developed. Sound has been provided with its unit of measurement and is but the last in a list of qualities which can now be handled quantitatively. It is true that some physical sciences, for example, physiology, are not, at the present time, predominantly statistical in character. It is also true that the work of the biochemist and the crystallographer is rapidly providing a quantitative, mathematical basis for sciences such as physiology.

In the social sciences, Mr. Durant said, it is possible to point to quantitative elements in a discipline so 'qualitative' as psycho-analysis. Freud develops the concept of displaceable energy which can attach itself to either the ego or the id. If there is reality in this concept, units of measurement will inevitably be developed, and actually work along these lines is being done at the present time. Prof. J. D. Bernal, in a recent paper read before the British Association, discussed the importance of obtaining statistical data by means of social surveys. "It is true that we have not got accuracy to seven figures, but without a snap survey action has to be taken with no figures at all, and even one figure arrived at roughly marks an enormous improvement, mathematically an infinite gain."

Mr. Durant thinks no one should hope that social science can be reduced solely to statistical data. In every investigation the man of science, whether or not he is aware of it, is employing a social theory. The problems he investigates, the concepts he adopts, are in all cases part of a much larger whole which, when consistently extended, temper of the physical scientist. He must try to test his hypotheses by observation, since experiment is largely denied to him. It is no argument that the social sciences are still young and must, therefore, be content with the qualitative methods which formerly characterized all sciences. The history of science indicates that progress is most rapid when there is the most vigorous insistence upon exact statistical measurement. Often the unit of measurement is difficult to develop and the technique of measurement presents even greater problems. It is the task of the social scientist to overcome these difficulties in his own field, for only by these means will he be able to eliminate the subjective bias which characterizes so much work which is being done at the present time in the social sciences.

Mr. 'Tom Harrisson, opposing Mr. Durant's arguments, stressed first of all the scope of disagreement and discussion. He agreed, of course, that quantitative methods are essential in all empirical studies. The difference of opinion here was not on the method but the emphasis; he rejected the conception that such research must be predominantly quantitative. It should be secondarily quantitative. Parallels with the physical sciences can be misleading, because they have already a living tradition of procedure, accepted research standards, a great body of proved and agreed basic theory and theses. The social sciences, unfortunately, developed much later, and there is still no common outlook or interchange with'n the whole field of social research. Empirical work has been scrappy and diffuse; much of it has been quantitative and the proportion has increased very much lately. The War has given a big fillip to the social sciences, for in the present periods of vast social and psychological change, new problems present themselves to Government departments and others, which urgently require attention from the psychologist, the sociologist and the student of public opinion.

Social science has not been well enough based and organized to respond to this call equally at all levels. It has tended to answer largely with quantitative studies, often without adequate appreciation of the background facts; there has been a tendency to assume that because some human factor can apparently be measured in percentage terms, the study is, therefore, necessarily. 'scientific'. The useful device known as the 'random sample' has provided an easy method for studying what people say. A few thousand interviews give a picture which will not be appreciably altered by interviewing the whole population. This quantitative method has, therefore, attracted much of recent social science. But because results are statistically consistent, it does not follow that they do not give a 'false' picture. By themselves they may be misleading, especially because we are still completely ignorant of the relationship between what people say to a stranger (the interviewer) and what they say to a friend; or between what people say, think and do. We are not yet in a position to know what weight can be attached to verbal behaviour; and at present we use interviews indiscriminately at our peril.

Mr. Harrisson feels that increased emphasis on this crude quantitative approach through the interview, without corresponding developments along other lines, such as observational technique, individual analysis, and penetration study of institutions, is unsatisfactory. In our present state of limited knowledge in social science, particular importance is attached to the full qualitative understanding of human phenomena, and at this stage the main function of quantitative methods, important as they are, is to act as a check, corrective and extension of the qualitative approach.

The social sciences have been slow to develop in Britain largely because the most educated and intelligent sections of the community are removed from the life of the mass of people who left school at or before the age of fourteen. It is difficult for the university professor to get down into the homes and hearts and minds of these people; few have done it objectively and over any length of time. Sociologists have long been conscious of this dilemma, and the sample method offered a way out-you ask people about themselves on a set questionnaire, or you pay others to go and ask for you, then tabulate the results in statistical detail. These results are important, in Mr. Harrisson's view, and there is room for many more of these studies, especially on the lines of the careful work done by the Wartime Social Survey ; but to suppose that social science is thereby scientific, and that it can in fact progress far along primarily quantitative lines before the fundamental premises of method are proved (for example, the validity of social class, the distribution of temperamental types, geographical factors in outlook) is an 
abuse of the word 'science'. This word is too loosely used in the social sciences, where many of those concerned have not been trained in scientific method but on philosophical lines, so that they too easily accept decimal points as objective data.

Mr. Harrisson urged that we need less partisanship in social science, which is still embryonic. Every method, every study at this stage should be encouraged. But the primary and vital acts of empirical social study must always be qualitative. Mr. Harrisson welcomes the increase in quantitative methods, but deplores the growth of the idea that only such methods are socially scientific, an idea which is reflected in the wording of Mr. Durant's submission on this occasion.

In the discussion that followed, a wide divergence of view was expressed.

Dr. Certrude Wagner spoke of the combined qualitative and quantitative method, and the need for social scientists to observe their own problems, to think them out qualitatively, then confirm their hypotheses by means of the quantitative method. She expressed the view that the only difference between $\mathrm{Mr}$. Durant and $\mathrm{Mr}$. Harrisson was as to whether there should be two hundred or two thousand interviews. Mr. Harrisson did not agree with Dr. Wagner on this, stating that there are sides of social science where no interviews are required, and current engrossment in the interview method was one of the things he was criticizing.

Dr. L. P. Richardson pointed out that the qualitative process is an essential initial step even in elaborate quantitative studies, as in the minutely accurate measurement work he had done in earlier days at the National Physical Laboratory. In comparing the weight of two bars of metal with the exactness required, it is still necessary to select the right bars for comparison by a qualitative act.

Dr. P. Senft discussed, in some detail, the philosophical relationship between quantitative and qualitative methods. Novelists like Proust and Stendhal have generally shown a far greater insight into human nature than psychologists and others approaching the same phenomena by quantitative methods.

Dr. Millais Culpin outlined some of his experiences during the work of the Industrial Health Research Board; he found the debate very like those he had heard long ago in medicine. It all boiled down to the old argument between those who were content to ask : What ? and those who were also concerned to know: Why? The quantitative method is likely, if handled thoughtlessly, to lead into an interminable pursuit of the What, though the social sciences must be concerned very much with the Why.

Prof. M. Ginsberg expressed himself in favour of Mr. Harrisson's views. The idea that social research methods could be predominatingly quantitative, and that qualitative methods must merge into quantitative, is absurd. The suggestion that there is no real distinction between the two approaches is unsound. Quality does not pass imperceptibly into quantity. The two are distinct, and there are, in addition, many sorts of quality. The quantitative and qualitative approaches in themselves involve different concepts.

Dr. G. H. Miles's experiences in the field of market research have disillusioned him about crude quantitative methods in social study. He has seen elaborate statistical investigations which were built up on unsound methodological assumptions, such as a survey in which people were interviewed on certain food habits. They claimed to eat more butter than they could conceivably have consumed. For people often do not know what they really do, and more often give answers which show them as respectable citizens; people always want 'to show up well' in the interview.

Mr. Harrisson said that the discussion had cleared the air in a useful way. So long as social scientists were ready to interchange views and argue things out in a friendly atmosphere, so long would this be a vital and growing subject. There has been too much sociological over-sensitiveness to criticism in the past. Elasticity of outlook is necessary for the advance of any science; the development of science is largely the process of correcting somebody else's error.

Mr. Durant expressed the view that there had been a substantial body of agreement, and for his part he could not see any real difference of opinion, for he felt that in the end everything became quantitative.

\section{PRODUCTION OF OPTICAL GLASS IN AUSTRALIA \\ By PROF. E. J. HARTUNG \\ University of Melbourne}

THE manufacture of optical instruments of many kinds for the Armed Forces has become an important section of the extensive programme of munitions production undertaken by Australia in the present emergency. Of necessity, a new and complex industry of this type had to cope with many initial problems, among which the supply of suitable optical glass soon began to cause anxiety. Some glass was obtained from Great Britain and the United States, but in the dark months following the capitulation of France optical glass of good quality and in sufficient quantity was not obtainable. In certain directions, the need became so great that spectacle lenses were used, and blocks of glass for the prisms of tank periscopes had to be made by welding together many sheets of plate glass.

The decision to undertake the production of optical glass in Australia was made in the latter half of 1940 , and subsequent events have shown most thoroughly the wisdom of this policy. About fourteen months after the first experimental work was initiated, fullscale production of glass of admirable quality commenced and has continued uninterruptedly, so that Australia is now not only completely independent of external supplies but is even exporting optical glass to other countries. This achievement has been due to close co-operation between the Chemistry Department of the University of Melbourne and the technical staff and facilities of Messrs. Australian Consolidated Industries Ltd., to which organization the actual production of the glass was entrusted. It is also a pleasure to record the very willing assistance received from the staff of the National Bureau of Standards, Washington, who placed freely at our disposal their extensive knowledge of technical details, thereby saving us much valuable time.

The original programme called for the production of six standard types of optical glass; this number was afterwards reduced to four which are now in production, but all six were made successfully in the 